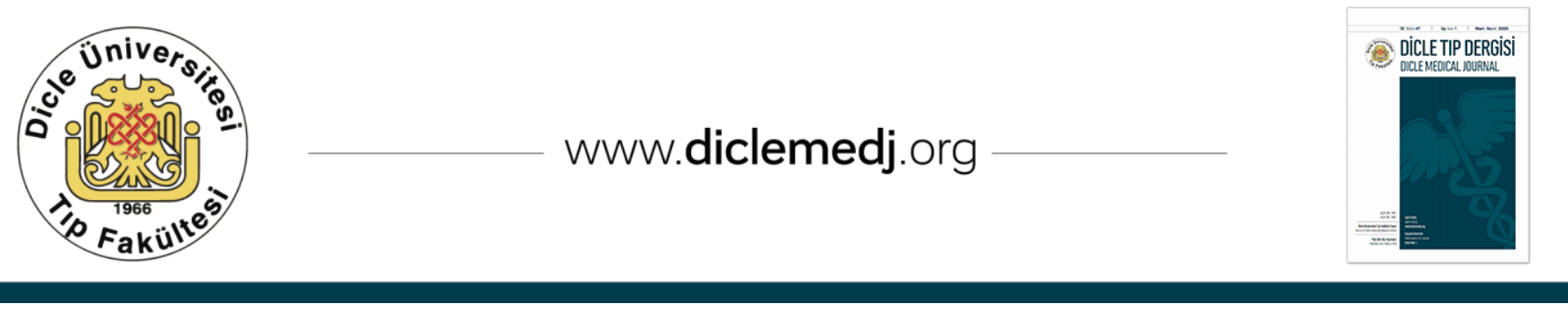

Özgün Araștırma / Original Article

\title{
Cerrahi Olarak Tedavi Edilen Distal Radius Kırıklarının Klinik Profili
}

\author{
Tolgahan Kuru1 ${ }^{\text {iD }, ~ O n u r ~ Y i l m a z ~}{ }^{1}$ iD \\ 1 Çanakkale Onsekiz Mart Üniversitesi Tıp Fakültesi, Ortopedi ve Travmatoloji Ana Bilim Dalı, Çanakkale, Türkiye
}

Geliş: 01.10.2019; Revizyon: 02.01.2020; Kabul Tarihi: 07.01.2020

Öz

Amaç: Bu çalışmanın amacı hastanemiz acil servisine başvuran ve kliniklerimizde distal radius kırığı nedeniyle cerrahi olarak tedavi edilen ve takipleri yapılan hastaların kırık paternleri ve uygulanan tedaviler ile kırık kaynaması arasındaki ilişkiyi araştırmaktır.

Yöntemler: Çalışmaya dahil edilen hastaların epikrizleri ve X-ray görüntüleri taranarak DRF’leri AO sınıflandırma sistemine göre sınıflandırılmıştır. Ayrıca hastaların yaşı, cinsiyeti, kırık oluşma paterni, uygulanan tedavi türü, konservatif olarak takip edilen hastalarda cerrahi yapılıp yapılmadığı, hastanede yatış süresi, izlem süresi, kaynama durumu ve komplikasyonları kaydedilmiştir. Hastalara uygulanan tedavilerin sonuçları komplikasyonlar ve kırık kaynaması açısından değerlendirilmiştir.

Bulgular: Kliniğimizde cerrahi olarak tedavi edilen distal radius kırıklarının 41'inde (\%78.8) doğrudan travma sonrası cerrahi planlanırken, 11'inde ise (\%21.2) acil serviste kapalı redüksiyon sonrası sirküler alçı uygulandıktan sonra poliklinik takiplerinde kırık hattında kayma olması üzerine cerrahi planlama yapılmıştır. Hastaların ortalama yatış süresi $3.5 \pm 1.8$ (min-maks: 1-10) gün olarak bulunmuştur. Ortalama izlem süresi $95.8 \pm 51.7$ gündür. Konservatif olarak takip edilen ve sonrasında cerrahi tedavi uygulanan hastaların yaş ortalaması doğrudan cerrahi uygulanan hastalardan istatistiksel olarak anlamlı şekilde daha yüksektir ( $\mathrm{p}=0.045)$. İki grup arasında preoperatif voler tilt, radial inklinasyon, radial uzunluk ve eklem basamaklanması açısından istatistiksel olarak anlamlı fark saptanmamıştır.

Sonuç: Hastalarımızda uygulanan çeşitli cerrahi tekniklerinin tümünde tam kaynama sağlanmış olup, bu teknikler arasında postoperatif komplikasyonlar açısından anlamlı fark saptanmamıştır.

Anahtar kelimeler: distal radius kırıkları, cerrahi tedavi, konservatif tedavi, komplikasyon, kaynama

DOI: $10.5798 /$ dicletip.706129

Yazışma Adresi/ Correspondence: Tolgahan Kuru, Barbaros Mh Çanakkale Onsekiz Mart Üniversitesi, 17020 Merkez, Çanakkale, Türkiye Tel: +90 286 2180018 E-mail: mdtolgahankuru@gmail.com 


\title{
Clinical Profile of Surgically Treated Distal Radius Fractures
}

\begin{abstract}
Objective: The objective of this study was to investigate fracture patterns and the relationship between the treatment methods used and fracture union in patients who presented to the emergency department of our hospital due to distal radius fractures and were surgically treated and followed out in our clinic.

Methods: Epicrisis and X-ray of the patients were screened and distal radius fractures were classified according to AO classification system. In addition, patients' age, gender, fracture pattern, treatment applied, whether surgery was performed in patients who were conservatively treated, duration of hospitalization, follow up duration, union status and complications were recorded. Treatment outcomes were evaluated in terms of complications and fracture union.
\end{abstract}

Results: Surgery was directly planned after trauma in 41 (78.8\%) patients, while surgery was planned in 11 (21.2\%) patients who underwent closed reduction in the emergency department upon deplacement in fracture line at outpatient clinical follow-up. The mean duration of hospitalization of the patients was found as 3.5 \pm 1.8 (min-max: 2.1-10) days. The mean follow up duration was found as $95.8 \pm 51.7$ days. The mean age of the patients who underwent conservative treatment and then converted to surgery was statistically significantly higher than the patients who directly underwent surgery $(\mathrm{p}=0.045)$. No significant difference was found between both groups in terms of preoperative volar tilt, radial inclination, radial length and joint cascade.

Conclusion: Complete union was found with various surgical techniques performed in our patients, while no significant difference was found between these techniques in terms of postoperative outcomes.

Keywords: Distal radius fractures, surgical treatment, conservative treatment, complication, union.

\section{GíRiş}

Distal radius kırıkları (DRF) en yaygın kırık türlerinden biri olup, Tüm acil kırıkların \%17\%18'ini oluşturmaktadır ${ }^{1,2}$. Bu kırıkların büyük bir oranı yaşlı bireylerde oluşmakla birlikte, tüm yaş gruplarında distal radius kırığı bulunan hastaların prevalansında büyük bir artıș olmuștur ${ }^{3}$. Yaș, radial uzunluk ve ilk dorsal açlanma dahil olmak üzere çok sayıda faktörün metafizeal instabilite üzerinde etkisinin bulunduğu ve böylelikle bu faktörlerin radiokarpal artikülasyonun mekaniklerini ve hizalanmasını değiştirdiği gösterilmiştir ${ }^{4}$. Her biri spesifik yaralanma mekanizmaları ve yaş gruplarına özgü olan farklı kırık paternleri vardır. Yüksek enerjili mekanizmalar yüksekten düşmesi trafik kazaları ve endüstriyel kazalarla ilişkili iken, düşük enerjili mekanizmalar ise kemiği zayıflatarak hastayı kırıklara yatkın bir hale getiren yapisal kondisyonlardan kaynaklanmaktadır ${ }^{5}$.
Tedavi açısından çeşitli seçenekler mevcuttur. Nonoperatif yönetim alçı ile kapalı tedaviden oluşur. Alçı ile immobilizasyon deplase olmayan kırıklar ve deplase stabil kırıklarda redüksiyon sonrası tatmin edici sonuçlarla uygulanmıştır. Bununla birlikte genç, aktif veya normal aktivitelerini geri kazanmak için yüksek beklentisi olan hastalarda cerrahi tedavi zorunlu olabilir. Operatif tedavi seçenekleri ise voler plaklama, $\mathrm{K}$ teli ile fiksasyon, intrafokal pinleme, eksternal fiksasyon, artroskopik destekli eksternal fiksasyon ve çeşitli açı redüksiyon internal fiksasyon yöntemleridir. Bu kırıkların çoğu konservatif olarak neden olmakla birlikte cerrahi tedavideki ilerlemeler nedeni ile cerrahi seçenek de popüler bir hale gelmiştir. Bu kırıkların şiddeti hastanın kemik mineral dansitesi ile doğrudan ilişkili olup, klinik sonuçlar da bu parametreye bağlıdır.

Bu çalışmanın amacı hastanemiz acil servisine başvuran ve kliniklerimizde cerrahi olarak tedavi edilen ve takipleri yapılan hastaların 
kırık paternleri ve uygulanan tedaviler ile kırık kaynaması arasındaki ilişkiyi araştırmaktır.

\section{YÖNTEMLER}

Distal radius kırığı nedeniyle hastanemizin kliniklerinde Ocak 2017 ve Aralık 2018 arasında tedavi edilen hastalar, hastane bilgi yönetim sistemi üzerinde retrospektif olarak taranarak değerlendirilmiştir. Çalışmaya dahil edilen hastaların epikrizleri ve $\mathrm{X}$-ray görüntüleri taranarak DRF'leri AO sinıflandırma sistemine göre sınıflandırılmıştır. Hastaların preoperatif voler tilt, radial uzunluk, radyal inklinasyon ve intraartiküler basamaklanmaları ölçülerek kaydedilmiştir. Ayrıca hastaların yaşı, cinsiyeti, kırık oluşma paterni, uygulanan tedavi türü, konservatif olarak takip edilen hastalarda cerrahi yapılıp yapılmadığı, hastanede yatış süresi, izlem süresi, kaynama durumu ve komplikasyonları kaydedilmiștir. Hastane kayıt sisteminde verilerinde eksiklik bulunan hastalar, aynı taraflı üst ekstremite kırığı olanlar, preoperatif X-ray görüntüsü bulunamayan hastalar ve açık distal radius kırıkları bulunanlar ile bilateral distal radius kırıklarında bilateral cerrahi uygulanan hastalar çalışma dışı bırakılmıştır. Çalışmamızda toplam 153 hasta değerlendirilmiş olup, 97 hasta konservatif olarak tedavi edildiğinden, 4 hasta ise verilerinde eksiklik olduğundan çalışma dışı bırakılmıştır.

Son olarak çalışmaya cerrahi yöntem ile tedavi edilen 52 hasta dahil edilmiş olup, bu hastaların 11'i başlangıçta konservatif olarak takip edilen, ancak sonradan kırık hattında deplasman olması nedeniyle cerrahi kararı verilen hastalardan, 41 tanesi ise travma sonrası başvuruda doğrudan cerrahi kararı alınan hastalardan oluşmaktadır.

\section{İstatistiksel Analiz}

Çalışmada elde edilen veriler SPSS v. 22.0 (IBM Statistical Package for Social Sciences, SPSS Inc., Chicago, IL, USA) paket programı kullanılarak analiz edilmiştir. Verilerin normal dağılımı Kolmogorov Smirnov yöntemi ile test edilmiştir. Normal dağılım göstermeyen değişkenler için nonparametrik testler kullanılmıştır. Kategorik veriler Ki kare testi ve Fisher Exact testi ile karşılaştırılmıştır. Normal dağılım göstermeyen sürekli veriler ise Kruskal Wallis ve MannWhitney $U$ testleri ile analiz edilmiştir. Tanımlayıcı istatistikler ortalama, standart sapma, çeyrek skala, minimum ve maksimum değerler olarak ifade edilmiştir. $p<0.05$ değeri istatistiksel olarak anlamlı kabul edilmiştir.

\section{BULGULAR}

Çalışmaya dahil edilen hastaların ortalama yaşı $51.57 \pm 19.01$ (min-maks: 18-84) ylldır. Hastaların 30'u $(\% 57,7)$ erkek ve 22'si $(\% 42,3)$ kadındir (E/K: 1.3/1.1). Hastaların AO sinıflandırmasına göre dağılımı Tablo I'de görülmektedir. Hastaların acil servise başvuru nedenleri Grafik 1'de görülmektedir.

Tablo I. Hastaların AO sınıflandırmasına göre dağılımı

\begin{tabular}{|c|c|c|c|c|}
\hline & AO Tip A & AO Tip B & AO Tip C & Toplam \\
\hline \multicolumn{5}{|l|}{ Cinsiyet } \\
\hline Erkek & $\begin{array}{l}6 \\
(\% 11,5)\end{array}$ & $\begin{array}{l}12(\% 23, \\
1)\end{array}$ & $\begin{array}{l}12(\% 23, \\
1)\end{array}$ & $\begin{array}{l}30 \\
(\% 57,7)\end{array}$ \\
\hline Kadın & $\begin{array}{l}9 \\
(\% 17,3)\end{array}$ & $5(\% 9,6)$ & $\begin{array}{l}8(\% 15,4 \\
)\end{array}$ & $\begin{array}{l}22 \\
(\% 42,3)\end{array}$ \\
\hline \multicolumn{5}{|c|}{ Cerrahi/Konservatif Tedavi } \\
\hline $\begin{array}{l}\text { Direkt } \\
\text { Cerrahi } \\
\text { Uygulananlar }\end{array}$ & $\begin{array}{l}11(\% 21, \\
2)\end{array}$ & $13(\% 25)$ & $17(32,6)$ & $\begin{array}{l}41(\% 78, \\
8)\end{array}$ \\
\hline $\begin{array}{l}\text { Konservatif } \\
\text { Takip } \\
\text { Edilenler }\end{array}$ & $4(\% 7,7)$ & $4(\% 7,7)$ & $3(\% 5,8)$ & $\begin{array}{l}\text { 11(\%21, } \\
2)\end{array}$ \\
\hline
\end{tabular}




\section{Acil Servise Başvuru Nedenleri}

\section{$10 \% 4 \%$}

$19 \%$

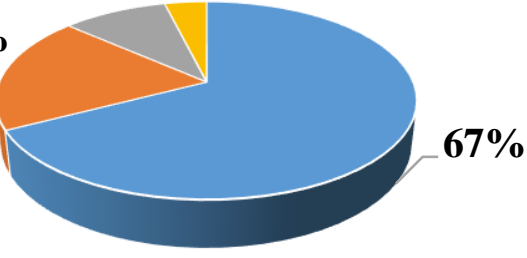

- Basit Düşme " Trafik Kazası " İş Kazası " Adli Vaka

Grafik 1. Hastaların acil servise başvuru nedenleri

Hastaların 29'unda $(\% 55,8)$ sol tarafta kırık mevcut iken, 23'ünde $(\% 44,2)$ ise kırık sağ taraftadır. Kliniğimizde cerrahi olarak tedavi edilen distal radius kırıklarının 41'inde $(\% 78,8)$ doğrudan travma sonrası cerrahi planlanırken, 11 'inde ise $(\% 21,2)$ acil serviste kapalı redüksiyon sonrası sirküler alçı uygulandıktan sonra poliklinik takiplerinde kırık hattında deplasman olması üzerine cerrahi planlama yapılmıştır. Hastalara uygulanan cerrahi türleri incelendiğinde; 36 hastada voler plak, 9 hastada el bileği fiksatörü + K teli fiksasyon ve 7 hastada $\mathrm{K}$ teli ile fiksasyon + sirküler alçı uygulanmıștır (Grafik 2).

\section{Uygulanan Cerrahi Teknikler}

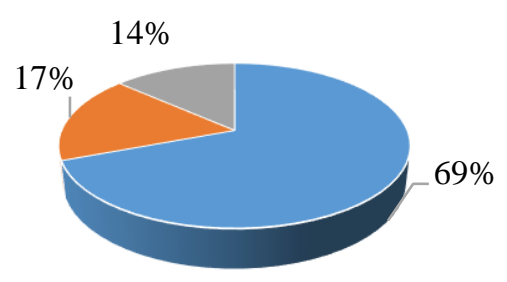

- Voler Plak

- El Bileği Fiksatörü + K Teli

- K Teli + Sirküler Alçı

Grafik 2. Uygulanan cerrahi teknikler

Hastaların hastaneye yatış ile cerrahi yapılan zamana kadar geçen preoperatif süreleri direkt cerrahi yapılan grupta $2.2 \pm 2.2$ gün iken, konservatif olarak izlenen ve poliklinik takiplerinde cerrahiye karar verilen hastalarda ise bu süre ortalama $13.4 \pm 14.6$ gün olmuştur. Hastaların ortalama yatış süresi $3.5 \pm 1.8$ (minmaks: 1-10) gün olarak bulunmuştur. Ortalama izlem süresi $95.8 \pm 51.7$ gündür.

Başlangıçta konservatif olarak takip edilen ve sonrasında cerrahi yapılan hastaların yaş ortalaması $61.3 \pm 19.3$ gün iken, ilk planda cerrahi yapılan hastaların yaş ortalaması $48.9 \pm$ 18.2 gün olarak saptanmıştır. Konservatif olarak takip edilen ve sonrasında cerrahi tedavi uygulanan hastaların yaş ortalaması doğrudan cerrahi uygulanan hastalardan istatistiksel olarak anlamlı şekilde daha yüksektir $(p=0.045)$. İki grup arasında preoperatif voler tilt, radial inklinasyon, radial uzunluk ve eklem basamaklanması açısından istatistiksel olarak anlamlı fark saptanmamıştır.

Çalışmaya dahil edilen 52 hastanın klinik takiplerinde 45 hastada komplikasyon gelişmezken, 3 hastada malunion, 1 hastada radiokarpal artroz, 1 hastada fleksor pollicis longus (FPL) ruptürü, 1 hastada implant başarısızlığı ve 1 hastada artroz + sudeck atrofisi görülmüştür. $\mathrm{Bu}$ hastalardan implant başarısızlığı olana dorsal plak uygulanırken, FPL ruptürü olan hastaya ise implant çıkartımı + tendon tamiri uygulanmıștır. Malunion gelişen 3 hastanın fiksatörü çıkartılarak plak uygulanmıştır. Cerrahi operasyon sonrası komplikasyon gelişen ve revizyon uygulanan bu 4 hastanın ortalama kırık kaynama süresi 81.5 \pm 8.2 gün olarak bulunmuștur. Revizyon cerrahisi yapılmayan hastalarda ise ortalama kaynama süresi $62.8 \pm 5.5$ gün olarak saptanmıştır. Hastalar postoperatif kırık kaynaması açısından değerlendirildiğinde; postoperatif komplikasyon gelişen ve revizyonu yapılan olgularla komplikasyon gelişmeyen hastaların tamamında tam kaynama olduğu görülmüştür.

Konservatif olarak takip edilip daha sonra cerrahi uygulanan hastaların \%18,2'sinde 
komplikasyon görülürken, doğrudan cerrahi kararı verilen hastaların ise \%12,2'sinde komplikasyon geliştiği saptanmıştır. Her iki grup arasında komplikasyon gelişimi açısından istatistiksel olarak anlaml bir fark saptanmamıștır ( $\mathrm{p}=0.63)$.

Postoperatif komplikasyonlar sınıflandırmasına göre değerlendirildiğinde, $\mathrm{AO}$ tip A hastaların 1'inde ekstaartiküler malunion görülürken, AO tip B hastaların 1'inde implant başarısızlığı ve 1'inde intraartriküler malunion, AO tip C hastaların 1'inde intraartriküler malunion, 1'inde PFL ruptürü ve 1'inde radiokarpal artroz + sudeck atrofisi saptanmıştır. Gruplar arasında komplikasyon gelişimi açısından istatistiksel olarak anlamlı fark saptanmamıştır ( $\mathrm{p}=0.4)$.

Hastalar 18-40 yll ( $\mathrm{n}=15), 41-60$ yll $(\mathrm{n}=22)$ ve $>60$ yll $(\mathrm{n}=15)$ olarak yaş gruplarına ayrıldığında; $18-40$ ve 41-60 yaş gruplarında birer hastada komplikasyon görülürken, $>60$ yaş grubunda ise 5 hastada komplikasyon saptanmıştır. Yapılan istatistiksel analizde hastalar $\leq 60$ ve $>60$ yaş olarak iki gruba ayrıldığında komplikasyon görülme sıklığının > 60 yaş grubunda istatistiksel olarak daha yüksek olduğu saptanmıștır $(p=0.016)$. AO sinıflandırmasına göre tip $A, B$ ve $C$ hastalar preoperatif voler tilt, radial uzunluk, radial inklinasyon ve eklem içi basamaklanma açısından değerlendirildiğinde; A grubunda radial inklinasyon açısının $B$ grubundan istatistiksel olarak daha yüksek olduğu saptanmıştır $(\mathrm{p}=0.014)$. Ayrıca radial uzunluk B grubunda $\mathrm{C}$ grubuna göre anlamlı olarak daha yüksek iken ( $p=0.030)$, voler tilt ise $C$ grubunda $B$ grubuna kıyasla anlamlı olarak daha yüksek saptanmıştır ( $\mathrm{p}=0.028)$.

\section{TARTIŞMA}

Distal radius kırıkları üst ekstremitenin en yaygın kırıkları olup, değişken derecelerde sakatlığa neden olurlar ${ }^{6}$. Tedavi seçeneklerinin değerlendirilmesi konusu literatürde halen tartışmalıdır. Bazı klinisyenler iyi fonksiyonel sonuçlar elde etmek amaciyla ulnar varyans ve volar tiltin düzeltilmesi gereken en önemli radyografik parametreler olduğunu ve diğer radyografik parametrelerdeki ufak değişkenliklerin kısa dönemli izlemde final sonucu etkilemediğini düşünmektedir7. Volar kilitli plakalamanın ulnar varyansı ve volar tilti düzeltme koruma yeteneği kompleks kırık türlerinde azalmaktadır 8 . Stabil olmayan distal radius kırıklarının volar kilitlemeli plakalama ile tedavisi önemli bir sekonder yer değiştirme olmaksızın iyi bir kırık redüksiyonuna yol açmaktadır 9 . Bununla birlikte Lutz K ve ark. ${ }^{10}$ cerrahi geçiren distal radius kırıklı yaşlı hastalarda komplikasyon oranlarının konservatif tedavi görenlere göre daha yüksek olduğunu bildirmiştir. Açı redüksiyon ve internal fiksasyon yapılan hastaların yaklaşı $\% 2$ 'sinde 30 gün içinde komplikasyon görülmektedir ${ }^{11}$. Bununla birlikte yapılan bir meta-analizin sonuçlarına göre internal fiksasyon grupları ile konservatif tedavi grupları arasinda komplikasyon oranları açısından anlamlı fark yoktur. Bizim çalışmamızda da başlangıçta doğrudan cerrahi kararı verilen hastalar ile konservatif olarak takip edilip daha sonra kırık hattında kayma oluşması nedeni ile cerrahi karar verilen hastalar arasında komplikasyon oranları açısından istatistiksel olarak anlamlı fark saptanmamıștır. Redüksiyon ve stabilizasyonun yöntemine bakılmaksızın distal radius kırığı tedavisinin amacı el bileği fonksiyonunun erken restorasyonudur.

Literatürde distal radius kırıklarının $\mathrm{AO}$ sistemine göre sınıflandırıldığı çalışmalar oldukça sınırlıdır'12,13. Bizim çalışmamız distal radius kırıklarının AO sistemine göre sınıflandırıldığı az sayıdaki çalışmadan biridir. Bulgularımıza göre en yaygın kırık türü AO tip C olarak saptanmıştır. Distal radius kırıklarının en yaygın mekanizması ayakta durma pozisyonundan uzanmış bir el üzerine 
düşmedir ${ }^{14,15}$. Bizim çalışmamızda da distal radius kırıklarının en yaygın oluşum mekanizması \%67 ile basit düşme olarak saptanmıştır.

Fanuele ve ark. ${ }^{16}$ tarafından Amerika Birleşik Devletleri'nde yapılan bir çalışmada başlangıçta cerrahi olarak tedavi edilen hastaların oranı konservatif olarak tedavi edilenlere göre anlamlı olarak yüksektir. Bizim çalışmamızda da hastaların çoğunda başlangıçta cerrahi tedavi kararı verilmiştir. 60 yaş üzeri hastaların konservatif yöntemlerle tedavi edilme olasılığ çeşitli nedenlerle daha fazladır. Bunun nedeni bu kişilerde yaralanmaların daha az şiddetli olması, kişinin cerrahiye karşı çıkması veya cerrahi riski artıran komorbiditelerin mevcudiyeti olabilir ${ }^{17}$. Bizim bulgularımıza göre başlangıçta konservatif tedavi kararı verilen hastaların yaş ortalamasının 61.3 yıl olması bu görüşü desteklemektedir.

Distal radius kırıkları tüm yaş gruplarında oluşmaktadır. $\mathrm{Bu}$ kırıkların oluşum mekanizması ile AO sınıflandırması arasında iyi bir korelasyon bulunmaktadır. Literatürde baskın el ile kırık tarafı arasında bir ilişki bulunmadığı bildirilmiştir ${ }^{17}$. Bizim çalışmamızda da kırık tarafları arasında anlamlı bir fark saptanmamıștır. Distal radius kırıklarının tedavisinde cerrahi veya konservatif tedavilerin seçimi konusunda görüş birliği bulunmamaktadır. Çalışmamızda da görüldüğü üzere başlangıçta konservatif tedavi gören, ancak sonrasında cerrahi tedaviye dönülen önemli sayıda hasta mevcuttur. Bununla birlikte hastaların tümünde tam kaynama sağlanması cerrahi yaklaşımın iyi bir seçenek olabileceğini düşündürmektedir. $\mathrm{Bu}$ konuda yapılacak kapsamlı ve çok merkezli, uzun izlem süreli prospektif çalışmaların önemli katkılar sağlayabileceğini düşünmekteyiz.

Çalışmamızın bazı sınırlılıkları mevcuttur. Çalışma retrospektif olarak tasarlanmış olup, nispeten az sayıda hastayı içermektedir. Ayrıca doğrudan konservatif olarak tedavi edilen hastalarla doğrudan cerrahi olarak tedavi edilen hastalar karşılaştırılamamıștır. Bununla birlikte çalışmamı literatürde AO sınıflandırmasına göre tedavi sonuçlarının analiz edildiği nadir çalışmalardan biridir.

Sonuç olarak, çalışmamızda yer alan hastalarda uygulanan çeşitli cerrahi tekniklerinin tümünde tam kaynama sağlanmış olup, bu teknikler arasında postoperatif komplikasyonlar açısından anlamlı fark saptanmamıştır. Önemli sayıda hastada konservatif tedaviden cerrahi yönteme dönüş yapıldığı göz önüne alındığında ilk değerlendirmede tedavi kararı alınırken pek çok faktörün ayrıntılı bir şekilde göz önünde bulundurulması gerektiğini düşünmekteyiz.

Etik Kurul Kararı: Çalışmaya başlamadan önce gerekli etik kurul onayı hastanemizin yerel etik kurulundan 12/06/2019 tarihli ve 2019-12 nolu karar ile alınmış ve çalışma Helsinki Deklarasyonu'nun ilkelerine uygun olarak gerçekleștirilmiştir.

Çıkar Çatışması Beyanı: Yazarlar çıkar çatışması olmadığını bildirmişlerdir.

Finansal Destek: Bu çalışma her hangi bir fon tarafından desteklenmemiştir.

Declaration of Conflicting Interests: The authors declare that they have no conflict of interest.

Financial Disclosure: No financial support was received.

\section{KAYNAKLAR}

1. Nellans KW, Kowalski E, Chung KC. The epidemiology of distal radius fractures. Hand Clin. 2012; 28: 113-25.

2. Court-Brown CM, Caesar B. Epidemiology of adult fractures: a review. Injury. 2006; 37: 6917.

3. O'Neill TW, Cooper C, Finn JD, et al. Incidence of distal forearm fracture in British men and women. Osteoporosis Int. 2001; 12: 555-8. 
4. Hove LM, Solheim E, Skjeie R, Sörensen FK. Prediction of secondary displacement in Colles' fracture. J Hand Surg Br. 1994; 19: 731-6.

5. Murray J, Gross L. Treatment of Distal Radius Fractures. J Am Acad Orthop Surg. 2013; 21: 502-5.

6. Tahririan MA, Javdan M, Nouraei MH, Dehghani M. Evaluation of instability factors in distal radius fractures. J Res Med Sci. 2013; 18: 892-6.

7. Dario P, Matteo G, Carolina C, et al. Is it really necessary to restore radial anatomic parameters after distal radius fractures. Injury. 2014; 45: 21-6.

8. Mignemi ME, Byram IR, Wolfe CC, et al. Radiographic outcomes of volar locked plating for distal radius fractures. J Hand Surg Am. 2013; 38: 40-8.

9. Ayong S, Traore A, Postlethwaite D, Barbier O. Functional evaluation of unstable distal radius fractures treated with an angle-stable volar Tplate. Acta Orthop Belg. 2014; 80: 183-9.

10. Lutz K, Yeoh KM, MacDermid JC, Symonette C, Grewal R. Complications associated with operative versus nonsurgical treatment of distal radius fractures in patients aged 65 years and older. J Hand Surg Am. 2014; 39: 1280-6.
11. Jiang JJ, Phillips CS, Levitz SP, Benson LS. Risk factors for complications following open reduction internal fixation of distal radius fractures. J Hand Surg Am. 2014; 39: 2365-72.

12. Brogren E, Petranek M, Atroshi I. Incidence and characteristics of distal radius fractures in a southern Swedish region. BMC Musculoskelet Disord. 2007; 31: 8: 48.

13. Broadbent MR, Quaba O, Hadjucka C, McQueen MM. The epidemiology of multifocal upper limb fractures. Scand J Surg. 2003, 92: 220-3.

14. Kreder HJ, Hanel DP, McKee M, et. al. Consistency of $\mathrm{AO}$ fracture classification for the distal radius. J Bone Joint Surg Br. 1996; 78: 726-31.

15. Owen RA, Melton LJ 3rd, Johnson KA, Ilstrup DM, Riggs BL. Incidence of Colles' fracture in a North American community. Am J Public Health. 1982; 72: 605-7.

16. Fanuele J, Koval KJ, Lurie J, et.al. Distal radial fracture treatment: what you get may depend on your age and address. J Bone Joint Surg Am. 2009; 91: 1313-9.

17. Koo OT, Tan DM, Chong AK. Distal radius fractures: an epidemiological review. Orthop Surg. 2013; 5: 209-13. 